\title{
EESTI KEELEKOGUKONNA SÄILIMISEST TAANIS
}

\author{
Maarika Teral ja Mari Allik \\ Tartu Ülikool
}

Kokkuvõte. Käesolev artikkel keskendub Taanis elavatele, põhiliselt Teise maailmasõja ajal ja järel sinna ümber asunud eestlaste ning nende järeltulijate eesti keele kasutuse vaatlemisele. Taani eestlaste kogukond on suhteliselt väike ning on jäänud teiste, suuremate väliseesti kogukondade varju. Taani eestlaste esimeseks põlvkonnaks nimetatakse artiklis neid eestlasi, kes tulid Taani Teise maailmasõja ajal. Teise põlvkonna moodustavad nende lapsed, kes on sündinud juba väljaspool Eestit. Esimene Taani eestlaste põlvkond, kes lahkus Eestist kodumaal omandatud eesti keelega ja on seda keelt läbi pagulasaastate alal hoidnud, on hääbumas, paljud neist on viimastel aastatel elust lahkunud. Pärast Teist maailmasõda või selle ajal sündinud teise põlvkonna taanieestlasi, kes räägivad eesti keelt, on vähem kui elusolevaid esimese põlvkonna taanieestlasi. Carol-Myers Scotton on välja toonud rea faktoreid, mis mõjutavad keele säilimist ja/või vahetust, jagades need kolme rühma: ühiskondlikud, grupisisesed ning individuaalsed (2006). Artiklis analüüsitakse Taani eestlaste eesti keele säilimist ja/või vahetust mõjutavaid tegureid, lähtudes Myers-Scottoni välja toodud faktoritest, tegemaks kindlaks, kas ülekaalus on keele säilitamist või vahetust soosivad tegurid.

Märksõnad: keelevähemus, identiteet, eestlased Taanis, kakskeelsus, keele säilimine ja vahetus, eesti keel

Abstract. Estonian language in Denmark. This article focuses on the use of the Estonian language by the first and second generation of Estonians, living in Denmark. The first generation of Estonians came to Denmark as a consequence of World War II, in 1944. This group of Estonians is defined in this study as the first generation. The second generation are the children of the first generation, born already in Denmark. First generation Estonians living in Denmark have preserved their mother tongue, however number of second generation 
Danish Estonians still speaking Estonian is very small. Carol MyersScotton discussed some specific factors that seem to influence language maintenance and shift (2006). She grouped the factors into three categories: the societal-level factors; the ingroup factors; and individual views and aspirations. Our analysis will be based on the factors contributing to the preserving of the L1 presented by Carol Myers-Scotton.

Keywords: language minority, identity, Estonians in Denmark, bilingualism, language maintenance and shiftuse, Estonian language

\section{Sissejuhatus}

Susanne Romaine (1997: 40) on seisukohal, et on olemas hulk väliseid tingimusi, mis keele säilimisele, vahetusele või surmale kaasa aitavad, kuigi ei määra mitte alati täielikult mingi keele saatust.

Carol-Myers Scotton (2006) on välja toonud faktorid, mis mõjutavad keele säilimist ja/või vahetust, jagades need kolme rühma: ühiskondlikud, grupisisesed ning individuaalsed. Käesolevas artiklis analüüsitakse neist, lähtudes Taani eestlaste eesti keele säilimist ja/või vahetust mõjutavaid tegureid, tegemaks kindlaks, kas ülekaalus on keele säilitamist või vahetust soosivad tegurid.

Taani eestlaste kogukond on suhteliselt väike. Esimesed eestlased asusid sinna elama juba 20. sajandi alguses. (Kulu 1992: 122) Täpsemad andmed varajaste väljarändajate kohta puuduvad. Pärast Teist maailmasõda oli Taanis tuhatkond Eesti sõjapõgenikku. Paljud neist ei jäänud Taani, vaid asusid sõjajärgsetel aastatel ümber teistesse riikidesse - Rootsi, USAsse, Austraaliasse jm (Kyhn 2001: 10). Kohale jäi sadakond eestlast, kelle hulgas naisi oli veidi rohkem kui mehi (IMMIBAS2 2008).

Praegu moodustavad enam kui kakskümmend aastat Taanis elanud eestlaste hulgas enamiku esimese põlvkonna väljarändajad, kes 1944. aasta paiku Eestist lahkudes olid lapsed või kuni 20-25aastased noored. Nende lapsed, kes on sündinud Taanis pärast Teist maailmasõda või selle ajal, kuuluvad Taani eestlaste teise põlvkonda. Teise maailmasõja 
keerises ümberasunud eestlaste ja nende järeltulijate kõrval elab Taanis ka pärast Eesti taasiseseisvumist ümberasunud eestlasi. Pikemalt on Taani eestlaste kogukonda ja nende kõneldavat keelt analüüsitud Maarika Terali magistritöös (2007) ja ülevaateartiklis „Eestlased ja eesti keel Taanis” (Teral ja Allik 2009).

Järgnevalt vaadeldakse pärast Teist maailmasõda Taani asunud eestlaste ja nende järeltulijate kogukonna võimalusi eesti keelt elus hoida, lähtudes Carol Myers-Scottoni (2006: 90) äratoodud keele säilitamisele kaasaaitavatest tingimustest. Carol Myers-Scottoni loetletud tingimused on eraldi iga punkti all välja toodud, loetelule järgnevad meie selgitused Taani olude kohta.

\section{Keele säilitamisele kaasaaitavad tingimused}

\subsection{Demograafilised tingimused, mis aitavad kaasa keele püsimajäämisele}

Carol Myers-Scotton (2006) on loetlenud järgmised demograafilised tingimused:

- horisontaalne kakskeelsus ühiskonnas - rahvusrühmad elavad omaette kogukonnana geograafiliselt eraldatud alal ning on sageli ükskeelsed ega puutu eriti kokku teiste rahvusrühmadega, kuigi riigis tervikuna esineb kakskeelsust;

- suurearvuline tihedasti koos elav kõnelejaskond;

- füüsiline eraldatus teise keele kõnelejatest (omaette asula või linnaosa);

- sisserändajate puhul suhteliselt hiljutine uude asukohariiki saabumine, kodumaaga tihedate sidemete säilitamine ja võimalus seda (sageli) külastada;

- L1 (esimesel keelel) on rahvusvahelise keele staatus. (Myers-Scotton 2006: 90)

Kui suurem hulk eesti sõjapõgenikke 1940. aastatel Taani jõudis, olid demograafilised tingimused järgmised: Taani oli rahvusriik, suuremaks rahvusvähemuseks oli saksa kogukond Lõuna-Taanis. Vahetult pärast II maailmasõja lõppu elas Taanis tuhatkond eestlast, kellest enamik oli sinna sõja ajal saabunud Saksamaa kaudu. Nende hulgas oli nii tsiviilpõgenikke kui ka 
Saksa sõjaväkke mobiliseerituid. Pärast Saksamaa kapitulatsiooni paigutati eestlased spetsiaalsetesse laagritesse, millest suurim asus Kopenhaagenis. (Eesti Kodu ajalugu 2007). Taani suhtumine oli selge - sõjapõgenikud pidid Taanist lahkuma nii kiiresti kui võimalik. (Kyhn 2001: 10)

Peter Kyhn on oma kirjutistes juhtinud tähelepanu sellele, et aastatel 1940-45 Taani välisminister olnud Gustav Rasmusseni arvates oli hea moodus Balti põgenikke Taanist lahkuma hirmutada Nõukogude Liidu sõjaväelaste lubamine põgenikelaagreid inspekteerima, mida tehti koostöös Taani politseiga. Meetmed mõjusid - enne 1950. aastat lahkus umbes 5600 kuuest tuhandest Taanis viibinud Balti põgenikust. (Kyhn 2001: 10). Ka enamik eestlastest hakkas elamistingimuste paranedes otsima elukohta väljaspool laagreid või lahkus Teise maailmasõja järgsetel aastatel teistesse riikidesse. Välis-Eesti Uuringute Keskuse andmetel läksid paljud neist naaberriikidesse Rootsi ja Saksamaale, kuid suunduti ka Austraaliasse, Kanadasse, USAsse ja Lõuna-Ameerikasse (Välis-Eesti Uuringute Keskus 2001). Niisiis ei elanud eesti keele kõnelejaskond tihedasti koos kauem kui 1950ndate alguseni, hiljem asusid Taani jäänud eestlased elama hajusalt taanlaste keskele (suur osa neist Sjællandi saarele ja Kopenhaagenisse).

Ka puudus eestlastel pärast Teist maailmasõda võimalus tihedateks kontaktideks Eestisse jäänud sugulastega. Taani nõukogudesõbraliku poliitika tõttu kartsid eestlased oma päritolu avalikult rõhutada ning Eestit külastada. Järgnevatel aastakümnetel suhtlesid vaid üksikud taanieestlased kodumaale jäänud sugulastega. Mitu küsitletut meenutas, et neid hirmutas fakt, et Taani võimud lubasid Nõukogude Liidu esindajatel põgenikelaagreid külastada ning seal kihutustööd teha.

N, 82: Siit ei saadetud vist kedagi tagasi, aga siin käis jo need kutsujad, tulge kodumaale ja ...

\footnotetext{
${ }^{1}$ Artiklis kasutatud tsitaadid pärinevad Maarika Terali poolt aastatel 1999_ 2006 tehtud intervjuudest Taani eestlastega. Säilitamaks informantide anonüümsus, on ära märgitud vaid nende sugu ja vanus lindistamise hetkel (vt ka Teral 2007).
} 
Uuesti tihenesid kontaktid Eestiga 1980. aastatel.

\subsection{Ametiga seotud tingimused:}

- töötamine koos inimestega, kellel on sama esimene keel;

- madal haridustase, mis piirab tööjõu liikumist;

- stabiilne arv töökohti ühiskonnas.

Ka ametiga seotud tingimused polnud täidetud eestlastel oli väga vähe võimalusi töötada koos oma rahvuskaaslastega. Paljudel väljarändajatel oli Eestis omandatud kesk- või kõrgharidus, Taani saabunud eestlaste hulgas oli Välis-Eesti Uuringute Keskuse andmetel (2001) nt ligikaudu viiskümmend ametnikku, üle kolmekümne üliõpilase, paarkümmend ärimeest, samuti arste ning medõdesid, hulk meremehi ning palju erinevate alade oskustöölisi, kuid neil puudus võimalus oma erialal tööd leida, seda eelkõige puuduliku taani keele oskuse tõttu. Enamik inimestest lahkus kolmandatesse riikidesse.

N, 82: Õieti, ma usun Taanis on kõige vaesem olnud see põgenike elu.. Taanis oli raske tööd saada tookord, nagu nü̈̈dki .... Kes vähegi kórgema haridusega, need katsusid Taanist ära saada ja siis jäid, kes ei olnd terved ja naised, kes ei olnud abielus. Aga muidu, kes vähegi sai, see läks ära...

M, 83: Tööd saada oli raske, palju olenes laagri juhtidest. /.... Erialalistele töödele ei lastud, näiteks oli aatomfü̈sik Helmuth Freymuth sunnitud välja rändama Argentiinasse juba 1947, kui avanes esimene võimalus...

Vahetult pärast Teise maailmasõja lõppu polnud töökohtade arv Taanis stabiilne. Sõjast laastatud riigis oli Taani eestlaste sõnul raske tööd leida.

N, 83: Euroopa riigid kiratsesid ju peale sõda kaua aega.

M, 83: Kuna polnud töövõimalusi, rändas enamik ja paremik välja, jäid vanad, invaliidid ja taanlastega abiellunud, kes olid pealegi üle kogu Taani laiali pillatud. 
Teise põlvkonna taanieestlased omandasid nii taani keele kui ka hariduse juba Taanis ning see lihtsustas erialase töö leidmist.

\subsection{Haridusega seotud tingimused:}

- parem, kui ametlikuks hariduse keeleks on esimene keel, vähemalt alg- ja põhikoolis;

- võimalus õppida esimest keelt eraldi ainena;

- kirjanduse kättesaadavus esimeses keeles;

- raadio- ja TV-saadete kättesaadavus esimeses keeles.

Esimene põlvkond taanieestlasi omandas emakeelse hariduse kodumaal enne sealt lahkumist. Kuigi eestikeelne kool tegutses Taanis põgenikelaagris kuni 1950. aastate alguseni, lõpetas see õpilaste vähesuse tõttu tegevuse ning teise põlvkonna eestlased said eesti keelt õppida ainult pühapäevakoolis.

N, 78: Siin oli ju põgenike kool, eesti laste kool põgenike laagris, üle kolme aasta oli ema [õpetaja], seal üks kaksteist viisteist eesti last käisid.

Taani koolides ei pakutud võimalust õppida eesti keelt eraldi ainena. Kuigi eestlastest lapsevanemad saatsid oma lapsi ka Rootsi täienduskooli, jäid eesti keele omandamise võimalused siiski piiratuks. See jättis teise põlve Taani eestlaste keeleoskusele tugeva jälje.

N, 82: No algul, aga kui hakkasin juba taani keelt rääkima, siis hakkasime, kui lapsed tulid, siis oli [kool]. Oma vanema poisiga ma rääkisin eesti keelt. Aga ei olnud teisi, kellega laps oleks võind koos mängida ja see kui läks kooli või lasteaeda ja unustas ära. Tänapäeval lapselapsed ka ütlevad "head ööd!” ja "maga hästi!"

Teise maailmasõja käigus lahkusid välismaale mitmed tunnustatud eesti kirjanikud. Sõjajärgsel perioodil hakati eestikeelset kirjandust välja andma Rootsis ning Taani eestlastel 
oli seda võimalik osta. Kodumaal avaldatud kirjandusele oli ligipääs raskem.

M, 83: Taanis ei olnud mingit raamatute väljaandmist, aga nii ORTO-l kui ka EKKO-l olid siin algul esindajad, raamatuid ja lehti telliti ja loeti.

Olukord on muutunud Eesti vabaks saades, tänapäeval on eestikeelset kirjandust võimalik tellida ka interneti teel. Mitmed Euroopa raadiojaamad edastasid raadiosaateid eesti keeles ka enne Eesti taasiseseisvumist, emakeelseid TV-saateid aga polnud eestlastel võimalik jälgida. Viimastel aastatel on Eesti raadio- ja telesaadete jälgimine interneti vahendusel siiski võimalikuks muutunud.

\subsection{Grupisisesed tingimused, mis aitavad emakeelt säilitada:}

- etnolingvistilise elujõulisuse üldine tajumine;

- tihedad grupisisesed sidemed, suhetevõrgustike olemasolu;

- unikaalse grupikultuuri olemasolu;

- grupi suhtumine keelde kui etnilisse sümbolisse;

- sidemed grupi L1 keele ja religiooni vahel;

- usk / veendumus, et grupp on eraldi (elujõuline) rahvus;

- rõhk grupisiseste suhete tihedusele;

- esimese keele (või murde) standardiseeritud kuju / kirjakeele olemasolu, mida enamik grupi liikmeid tunneb;

- kirjalik traditsioon;

- keelega seotud institutsioonide olemasolu (keelekoolid jm organisatsioonid)

Etnolingvistilise elujõu mudeli esitasid 1997. aastal Giles, Bourhis ja Taylor (Myers-Scotton 2006: 74), kelle järgi grupi etnolingvistilise elujõu määravad sotsioloogilised tegurid (grupi staatus, keele kõnelejate hulk, ametlike institutsioonide toetus).

Myers-Scotton (2006: 72-73) on rõhutanud, et keelte säilimise seisukohalt on olulised keelekogukonna grupisisesed suhted, nii tugevad kui nõrgad, sest just nende kaudu levivad 
grupisisesed uuendused ja muutused. Grupisisesed suhted muudab tugevaks nende suur tihedus (igapäevased suhted pereliikmete, lähedaste sõprade, töökaaslastega), nagu ka suhete lähedus - kas arutatakse intiimseid peresiseseid küsimusi jne.

Taani eestlaste kogukond oli suhteliselt väike ja grupisisesed sidemed, mis esimestel aastatel olid suhteliselt tihedad (lisaks peresisestele tugevatele sidemetele ka nn nõrgad sidemed - aktiivne osalemine kohalike eestlaste seltsielus, Eesti Kiriku töös jne), muutusid aastate jooksul eestlaste lahkudes teistesse riikidesse nõrgemaks. Tihedamaks jäid siiski perekondlikud sidemed Rootsis elavate sugulastega. Võrreldes Taaniga tuli Teise maailmasõja järel Rootsi palju enam Eesti sõjapõgenike ja kuigi nende täpset hulka ei ole teada, arvab Kangro, et Rootsis võis 1945. aastal olla 26-27000 eestlast (Kangro 1976: 42).

M, 52: Ma õppisin eesti keelt, kui ma olin väike last, ma kuulsin nagu, kui ema rääkis sugulastega, see tähendab, meie käisime väga tihti Rootsi, sääl on väga palju sugulased, kõik Eestist tulnud.

Carol Myers-Scotton (2006) juhib tähelepanu ka etnolingvistilise elujõu tajumisele ühe olulisema grupisisese tegurina, mh niinimetatud subjektiivse etnolingvistilise elujõu (grupiliikmete hinnang grupi staatusele teiste gruppidega võrreldes) tähtsusele keele säilimises või vahetuses.

Põhiosa eesti immigrante saabus Taani Teise maailmasõja ajal või järel ning nad paigutati elama põgenikelaagritesse. Taanlaste suhtumist on taanieestlased meenutanud erinevalt, sõltuvalt kogemustest, mis kellelegi olid osaks saanud.

N, 82: Vaat siis ei olnud ka niisugusi kogemusi, sakslasi nad [taanlased] vihkasid, aga teiste vastu ei olnd neil midagi.

N, 82: Aga minule tundub, et Taani oli tookord [Teise maailmasõja järel] palju sõbralikum.

M, 52: Ma mõtlen, et võibolla seepärast, et eestlased ja lätlased, need oskasid väga hästi saksa keelt ja siis kõik need on fašistid ja me viskame need ära /.../ nad lihtsalt ei saanud siin elada, see oli väga-väga raske, ja see oli ka väga raske kohta saada. 
Eestlased tundsid, et Taani ametlik poliitika ei olnud ei Teise maailmsõja järel ega ka hiljem Balti põgenikke toetav. (Kyhn 2001: 10) Ametlike institutsioonide leige huvi taga nähti Taani valitsuse Nõukogude-sõbralikku poliitikat.

N, 78: Kaubitsemine Venemaaga oli suur, taanlane on ju alati olnud väikese maalapi omanik. Ja see suur huvi selle Venemaa vastu, [...] venelased sõdisid sakslaste vastu, et siis suur sümpaatia tekkis. Sest nad ei teadnud poliitikast mitte midagi.

Kuigi Taani eestlased üritasid eestlust edasi viia, on intervjueeritud siiski nentinud, et see oli Taanis keeruline, kuna eestlasi oli seal väga vähe.

Eestlased mõistsid küll keele olulisust mingisse gruppi kuulumisel, näiteks pidasid oluliseks õppida ära taani keel, selleks et neid uuel kodumaal omadena koheldaks, kuid sageli tähendas see, et eesti keele õppimine ja kõnelemine soikus:

N, 86: Jah, me rääkisime [eesti keelt] vahel, aga me rääkisime niisama palju ka taani keelt ja see oli siis palju kord, meil olid ju seal taani abikaasad kõigil, siis tuli see nagu iseenesest, et nende pärast, et kui nemad ka olid ühes, siis rääkisime jo taani keelt.

N, 86: Meil oli tööd tõepoolest niipalju teha, et õppida taani kombeid ja taani keelt ja tähendab, meist pidid saama niiütelda taanlased, muidu, jo, me olime uhked, et me olime teistmoodi ...

Hoolimata soovist end uuel kodumaal võimalikult hästi sisse seada ei loobunud mõned vanema põlve eestlastest oma emakeelest ja nägid seda siiski olulise rahvuse ja kultuurisümbolina:

N, 78: Minu ema ja, tema nii-ütelda kunagi óieti ei oppind taani keelt ära. [...] Tema oli ka eestlane, tema end ümber teha ei lasknud, ema..

N, 82: Mina sõitsin emaga bussis, ja ema ei saanud niisugustest asjadest aru, et keeratakse ringi, kui kuuldakse välismaa keelt bussis. Me ei olnud ju turistid ja ema räägib ka 
kõvasti eesti keelt, ma ütlen, ema, räägi tasem, inimesed hakkavad vaatama, ei taha.

Kui rääkida sidemetest grupi keele ja religiooni vahel, siis nii eestlaste kui ka taanlaste hulgas on enamuses luteri kiriku liikmed. Taanis moodustati 1952. aastal EELK LõunaRootsi koguduse osana Kopenhaageni pihtkond, mille jumalateenistusi peetakse tavaliselt kolm korda aastas Hans Tauseni kirikus. Eesti kirikul on kindlasti olnud oluline roll Taani eestlaste identiteedi säilitamises, ühelt poolt eestikeelsete jutlustega, teisalt sellega, et lisaks teenistustele korraldati ka koosviibimisi, kuhu olid oodatud nii pihtkonna liikmed kui ka külalised ning kus eestlastel avanes soodne võimalus omavahel suhelda.

Eestikeelsete koolide puudumise tõttu omandasid teise põlve eestlased keele tavaliselt suulise suhtlemise kaudu, mõned neist eelistavad eesti keeles üldse mitte kirjutada, kartes vigu teha.

\subsection{Individuaalsed vaated ja taotlused, mis aitavad kaasa keele säilimisele:}

- suhtlusvõrgustiku olemasolu - suhted teiste grupi liikmetega (nii tugevate kui nõrkade sidemete olemasolu grupisisese liikmeskonnaga):

- positsioon grupisisestes suhetevõrgustikes (tsentraliseeritus) - seda hinnatakse grupisiseste suhete hulga järgi, nagu ka positsiooni põhjal võrgustikus; mida olulisemat rolli mängib keegi grupis, seda enam on tal ka mõju grupile kui tervikule;

- kiindumus keelde kui identiteedi alusesse;

- grupiidentiteedi tähtsustamine vastandatuna identiteedile laiemas mõttes;

- perekondlike sidemete rõhutamine;

- grupiliikmete madal haridustase;

- mitte eriti kõrge hinnang haridusele teises (domineerivas) keeles;

• vähesed võimalused ametit vahetada; 
- grupi religiooni säilitamine (kui see erineb teise keele kõnelejate religioonist).

Individuaalsed vaated ja taotlused on tihedalt seotud grupisiseste suhetega, (nt grupisiseste suhete tihedus ning inimeste positsioon suhtevorrgustikus), nii et neid on raske lahus vaadelda. Taani eestlaste grupisisesed suhted olid vahetult pärast Teist maailmasõda tihedad, osalt seetõttu, et pärast Saksamaa kapitulatsiooni paigutati põhiosa eestlasi suuremate gruppidena elama spetsiaalsetesse põgenikelaagreisse. Vastavalt ametlikele allikatele oli tollal Taanis tuhatkond eestlast, kes said põgeniku staatuse. Laagris toimusid seltskondlikud ja kultuuriüritused (vt Eesti Kodu ajalugu), mis aitasid Taani eestlaste omavahelisi suhteid tihendada. 1948. aastal taaselustati ka selts Eesti Kodu, mille ümber keskendus järgnevatel aastakümnetel Taani eestlaste seltskondlik elu. Kuid ehkki eestlaste grupisisesed kontaktid säilisid, olid pärast sõjajärgsete aastate intensiivset väljarännet aktiivsed (ning seega grupisisestes võrgustikes kesksel kohal) u 20-30 inimest.

M, 83: Kopenhaagenis oli ka kõige suurem eestlaste kogukond, vist 50-60 ringis, aga neist vôttis [seltsielust] aktiivselt osa ainult 20-30, teised elasid oma elu, mitmed tulid välja alles Eesti taasvabanemise kulgedes.

Uues riigis kohanemiseks püüti tutvuda kohaliku keele ja kultuuriga. Paljud eestlased, kes Taani saabusid, olid kodumaal omandanud kesk- või kõrghariduse ja valdasid mitut keelt.

N, 78: Taani oli ju hoopis teine maa, kui mina siia tulin. Ma tundsin, et ma olin koolis rohkem õppinud, kui taanlased minu vanuses. Ja Taani professorid on mind eelistanud.

Taani keele omandamine aitas neil kergemini erialaseid töökohti leida ning seega hinnati taani keele oskust (nagu ka selles keeles omandatud haridust) kõrgelt.

M, 83: Ise õppisin taani keele taanlastega suheldes ja lugedes, tähendab iseseisvalt. Nii korralikult, et 1949. aastal sain ülikoolis selles keeles sooritatud filosoofia eksamis maksimumhinnangu. Nii olen ise óppinud ka teisi keeli. 
Eesti keelekogukonna säilimisest Taanis 12

\section{Kokkuvõte}

Järgnevas tabelis on toodud kokkuvõtlik ülevaade erinevatest keele säilimisele kaasaaitavatest teguritest ning sellest, millised neist olid Taani eestlaste puhul täidetud ning millised mitte. Tabelis on +-märgiga tähistatud täidetud tingimused, --märgiga täitmata tingimused, -märgiga osaliselt täidetud tingimused.

Eesti kogukonnas muutusid paljud tingimused 1950. aastatel, kümnendi alguses olid paljud eestlased rännanud edasi uutesse asukohamaadesse, kuid esialgu käisid kohalejäänud eestlased veel tihedasti läbi nii üksteise kui ka rootsieestlastega, neil oli elav seltsielu jne. Seepärast on tabelis märgitud 1950ndate keskpaik valitud tinglikult ühe perioodi lõpuajaks.

Tabel 1. Taani eestlaste keele säilimist soodustavad tegurid

\begin{tabular}{|c|c|c|c|c|}
\hline $\begin{array}{l}\text { a) Demograa- } \\
\text { filised }\end{array}$ & $\begin{array}{l}\text { b) Ametiga } \\
\text { seotud }\end{array}$ & $\begin{array}{l}\text { c) Hari- } \\
\text { dusega } \\
\text { seotud }\end{array}$ & $\begin{array}{l}\text { d) Grupisise- } \\
\text { sed }\end{array}$ & $\begin{array}{l}\text { e) Individuaal- } \\
\text { sed vaated ja } \\
\text { taotlused }\end{array}$ \\
\hline $\begin{array}{l}\text { Horisontaalne } \\
\text { kakskeelsus } \\
\text { ühiskonnas }\end{array}$ & $\begin{array}{l}\text { Töötamine } \\
\text { koos rahvus- } \\
\text { kaaslastega, } \\
\text { (sama } \\
\text { esimene keel) } \\
\text { - }\end{array}$ & $\begin{array}{l}\text { Ametlikuks } \\
\text { hariduse } \\
\text { keeleks on } \\
\text { L1, vähemalt } \\
\text { alg- ja } \\
\text { põhikoolis } \\
\sim \\
\text { Eestis } \\
\text { hariduse } \\
\text { saanutel + } \\
\text { / Taanis - }\end{array}$ & $\begin{array}{l}\text { Etnolingvistilise } \\
\text { elujõulisuse } \\
\text { üldine tajumine } \\
\text { (arusaamine) } \\
\sim\end{array}$ & $\begin{array}{l}\text { Suhetevorrgustik } \\
\text { u olemasolu - } \\
\text { tihedad suhted } \\
\text { teiste grupi } \\
\text { liikmetega. } \\
\text { 1950ndate } \\
\text { keskpaigani + } \\
\text { / hiljem suhted } \\
\text { nõrgemad }\end{array}$ \\
\hline $\begin{array}{l}\text { Suurearvuline } \\
\text { tihedasti koos } \\
\text { elav } \\
\text { kõnelejaskond } \\
\text { - }\end{array}$ & $\begin{array}{l}\text { Madal } \\
\text { haridustase } \\
\text { piirab tööjõu } \\
\text { liikumist } \\
\text { - }\end{array}$ & $\begin{array}{l}\text { Võimalus } \\
\text { oppida } \\
\text { esimest keelt } \\
\text { eraldi ainena } \\
\sim \\
\text { Kuni 1950te } \\
\text { keskpaigani } \\
+ \text {, hiljem - }\end{array}$ & $\begin{array}{l}\text { Tihedad } \\
\text { grupisisesed } \\
\text { sidemed } \\
\sim \\
\text { 1945-60te } \\
\text { alguseni + / } \\
\text { hiljem } \\
\text { nõrgenevad - }\end{array}$ & $\begin{array}{l}\text { Positsioon gru-" } \\
\text { pisisestes } \\
\text { suhetevõrgustik } \\
\text { es } \\
\text { Aktiivseid } \\
\text { osalejaid u 20- } \\
30\end{array}$ \\
\hline
\end{tabular}


Eesti keelekogukonna säilimisest Taanis 13

\begin{tabular}{|c|c|c|c|c|}
\hline $\begin{array}{l}\text { L1 keele } \\
\text { kõnelejaskonna } \\
\text { füüsiline } \\
\text { eraldatus teise } \\
\text { keele } \\
\text { kõnelejatest- }\end{array}$ & $\begin{array}{l}\text { Stabiilne arv } \\
\text { töökohti } \\
\text { ühiskonnas } \\
+ \\
\text { Erialasel tööl } \\
\text { - }\end{array}$ & $\begin{array}{l}\text { Kirjanduse } \\
\text { kättesaadavus } \\
\text { L1-s } \\
+\end{array}$ & $\begin{array}{l}\text { Unikaalse } \\
\text { grupikultuuri } \\
\text { olemasolu } \\
+\end{array}$ & $\begin{array}{l}\text { Kiindumus } \\
\text { keelde kui } \\
\text { identiteedi } \\
\text { alusesse } \\
+\end{array}$ \\
\hline $\begin{array}{l}\text { Tihedad } \\
\text { sidemed } \\
\text { kodumaaga, } \\
\text { saavad seda } \\
\text { kergesti } \\
\text { külastada } \\
\text { - }\end{array}$ & & $\begin{array}{l}\text { Raadio- ja TV } \\
\text { saadete } \\
\text { kättesaadavus } \\
\text { esimeses } \\
\text { keeles. } \\
\sim \\
\text { Raadiosaated } \\
\text { kättesaadavad } \\
\text {, televisioon } \\
\text { mitte }\end{array}$ & $\begin{array}{l}\text { Grupi } \\
\text { suhtumine } \\
\text { keelde kui } \\
\text { etnilisse } \\
\text { sümbolisse } \\
+\end{array}$ & $\begin{array}{l}\text { Grupiidentiteeti } \\
\text { tähtsustatakse } \\
\text { vastandatuna } \\
\text { identiteedile } \\
\text { laiemas mõttes } \\
+\end{array}$ \\
\hline \multirow[t]{6}{*}{$\begin{array}{l}\text { L1 on rahvus- } \\
\text { vahelise keele } \\
\text { staatus } \\
\quad-\end{array}$} & & & $\begin{array}{l}\text { Sidemed grupi } \\
\text { keele ja } \\
\text { religiooni vahel } \\
\text { Eestikeelse } \\
\text { kiriku } \\
\text { olemasolu } \\
+\end{array}$ & $\begin{array}{l}\text { Rõhutatakse } \\
\text { perekondlikke } \\
\text { sidemeid } \\
\quad-\end{array}$ \\
\hline & & & $\begin{array}{l}\text { Usk/ } \\
\text { veendumus, et } \\
\text { grupp on eraldi } \\
\text { (elujõuline) } \\
\text { rahvus } \\
+\end{array}$ & $\begin{array}{l}\text { Madal } \\
\text { haridustase } \\
\text { - }\end{array}$ \\
\hline & & & $\begin{array}{l}\text { Rõhk asetatud } \\
\text { grupisiseste } \\
\text { suhete } \\
\text { tihedusele } \\
\text { 1945-1955 } \\
+ \\
\text { hiljem vähem }\end{array}$ & $\begin{array}{l}\text { Ei hinnata eriti } \\
\text { kõrgelt haridust } \\
\text { teises } \\
\text { (domineerivas) } \\
\text { keeles } \\
\text { - }\end{array}$ \\
\hline & & & $\begin{array}{l}\text { Esimese keele } \\
\text { kirjakeele (või } \\
\text { murde) } \\
\text { olemasolu, mida } \\
\text { enamik grupi } \\
\text { liikmeid tunneb } \\
+\end{array}$ & $\begin{array}{l}\text { Vähesed } \\
\text { võimalused } \\
\text { ametit vahetada } \\
\text { - }\end{array}$ \\
\hline & & & $\begin{array}{l}\text { Keelega seotud } \\
\text { institutsioonide } \\
\text { olemasolu } \\
\text { (keelekoolid } \\
\text { jm) } \\
\text { - }\end{array}$ & $\begin{array}{l}\text { Grupi religiooni } \\
\text { säilitamine (kui } \\
\text { see erineb teise } \\
\text { keele kõnelejate } \\
\text { religioonist): } \\
\text { Sama religioon }\end{array}$ \\
\hline & & & $\begin{array}{l}\text { Kirjalik } \\
\text { traditsioon }\end{array}$ & \\
\hline
\end{tabular}


Kokkuvõtvalt võib öelda, et on vähe tegureid, mis soosivad Taani eestlaste eesti keele säilimist. Kõige paremini on täidetud grupisisesed tingimused; hariduse ja ametiga seotud tingimused on täidetud osaliselt (kuigi tööd oli võimalik leida, polnud eestlastel sageli võimalik töötada oma erialal), demograafilistest tingimustest pole aga ükski täidetud. Taani eestlaste esimene põlvkond on küll eesti keele säilitanud, kuid juba teise põlvkonna hulgas on eesti-taani kakskeelseid vähe ning domineerivaks keeleks on taani keel.

Eesti taasiseseisvudes on Taani eestlaste ja eesti keele olukord mõnevõrra muutunud. Taas on avanenud võimalus takistusteta kodumaad külastada. Taani on tööle ja elama asunud noori eestlasi Eestist, kes on elavdanud ja uuendanud Eesti Kodu tegevust (vt lähemalt Eesti Kodu ajalugu 2007). Kasutusele on tulnud internet, mis võimaldab jälgida eestikeelseid tele- ja raadiosaateid, lugeda Eesti ajalehti, tellida eestikeelset uudiskirjandust. Samas puudub eesti keelel Taanis järjepidevus, sest keelt ei antud edasi järgmistele põlvedele ja koos esimese põlvkonna hääbumisega jäävad eestluse põhikandjaks Eestist alates 1990ndatest Taani elama asunud inimesed.

\section{Aadress:}

Maarika Teral ja Mari Allik

eesti keele võõrkeelena osakond

Tartu Ülikool

Ülikooli 18

50090 Tartu

E-mail:maarika.teral@ut.ee,mari.allik@skynet.be

\section{Kirjandus ja allikad}

Eesti Kodu ajalugu (2007) = Ühenduse „Eesti kodu” koduleht <http://www.eestikodu.dk/art_ajaluguee.htm> Vaadatud: 25.07.2007

IMMIBAS2 $(2008)=$ Database over indf $\phi$ dsretstildeling 1776-. DDD Indvandrerarkivet. <http://www.immigrantmuseet.dk/IMMIBAS/ indfoedsretstildelinger_1776.htm $>$ Vaadatud: 30.04.2008 
Eesti keelekogukonna säilimisest Taanis 15

Kangro, Bernard (1976) Estland i Sverige. Lund: Eesti Kirjanike Kooperatiiv.

Kulu, Hill (1992) Eestlased maailmas. Ülevaade arvukusest ja paiknemisest. Tartu: Tartu Ülikooli kirjastus.

Kyhn, Peter (2001) „Estland i Danmark 1940-1991”. Dansk-Estisk Selskab nr 33, 11/2001, 9-14. Odense: Micro Forma.

Myers-Scotton, Carol (2006) Multiple voices: an introduction to bilingualism. Oxford: Blackwell Publishers.

Romaine, Suzanne (1997) Bilingualism. Oxford: Blackwell Publishers.

Teral, Maarika (2007) Taani eestlaste keelest. Käsikirjaline magistritöö. Tartu: Tartu Ülikool. Eesti ja üldkeeleteaduse instituut.

Teral, Maarika ja Mari Allik (2009) „Eestlased ja eesti keel Taanis“. Kogumikus Eestlased ja eesti keel välismaal. Tallinn: Eesti Keele Sihtasutus

Välis-Eesti Uuringute Keskus (2001) = Välis-Eesti Uuringute Keskuselt saadud andmed II maailmasõja ajal ja järel Taani saabunud eestlaste kohta 
Eesti keelekogukonna säilimisest Taanis 16 